\title{
Severe non-traumatic bleeding events detected by computed tomography: do anticoagulants and antiplatelet agents have a role?
}

\author{
Olivier Risch ${ }^{1}$, Agaicha Alfidja ${ }^{1}$, Aurelien Mulliez², Anderson H Amani ${ }^{3}$, Louis Boyer ${ }^{1}$, Lionel Camilleri ${ }^{3}$ \\ and Kasra Azarnoush $h^{3,4^{*}}$
}

\begin{abstract}
Purpose: Bleeding is the most common and most serious complication of anticoagulant (AC) and antiplatelet agents (APA) which are increasingly used in every day practice. The aim of this study was to enlist and analyze the most severe bleeding events revealed during computed tomography scanner (CT scan) examinations over a 1-year period at our University Hospital and to evaluate the role of ACs and APAs in their occurrence.

Methods: This descriptive monocentric retrospective study included all patients who benefited from an emergency $\mathrm{CT}$ scan with a diagnosis of severe non-traumatic bleeding. Patients were divided into two groups: those treated with ACs and/or APAs, and those not treated with ACs or APAs.

Results: After applying the inclusion criteria, 93 patients were enrolled. Sixty-one patients received an anticoagulant or antiplatelet treatment, and 32 did not receive any AC or APA therapy. Seventy nine percent presented with an intracranial hemorrhage, $17 \%$ with a rectus sheath or iliopsoas bleeding or hematoma, and $4 \%$ with a quadriceps hematoma. Only patients who received ACs or APAs suffered a muscular hematoma ( $p<0.0001)$. Among patients treated with vitamin $\mathrm{K}$ antagonists, 6/43 (14\%), had an international normalized ratio (INR) higher than the therapeutic range (INR $>3$ ).

Conclusions: In our series, intracranial hemorrhage was preponderant and muscular hematomas occurred exclusively in patients treated with ACs and/or APAs. This study needs to be extended to evaluate the impact of new anticoagulant and antiplatelet agents.
\end{abstract}

Keywords: Intracranial hemorrhage, Muscular hematoma, Anticoagulant, Antiplatelet agents, CT-scan

\section{Background}

Bleeding is regarded as severe if it has hemodynamic consequences that require transfusion or a hemostatic therapeutic procedure, if vital or functional prognosis is compromised due to its location, or if it cannot be controlled by the usual means. When none of these criteria is present, hemorrhage is qualified as non-severe [1].

Anticoagulants (AC) are the treatment for many pathological conditions, such as venous thromboembolic disease, atrial fibrillation, as well as for patients with

\footnotetext{
* Correspondence: kazarnoush@chu-clermontferrand.fr

${ }^{3}$ Heart surgery Department, G. Montpied Hospital, Clermont-Ferrand University Hospital, Clermont-Ferrand 63000, France

${ }^{4}$ INRA, UMR 1019 Nutrition Humaine, Saint Genès Champanelle, France Full list of author information is available at the end of the article
}

mechanical heart valve prosthesis. Although their efficacy has been widely acknowledged, these drugs can lead to complications, the most frequent and severe of which are hemorrhagic events [1].

Currently, more than 900,000 patients receive vitamin-K antagonists (VKA) in France [2]. VKAs are responsible for most iatrogenic complications [3]. In France, the cost of these complications is more than 300 million Euros per year [3] and anticoagulant-related hemorrhagic accidents, especially directly caused by VKAs, are responsible for almost 20.000 hospitalizations per year, with a 5/100 patient-year incidence of severe bleeding events and a 1/100 patient-year incidence of fatal events.

Besides anticoagulants (AC), antiplatelet agents (APA) also induce an important risk for major bleeding. This risk 
of a hemorrhagic event is nearly doubled when antiplatelet agents are used as a bitherapy [4].

Many factors contribute to the hemorrhagic complications that can occur under anticoagulant therapy $[4,5]$. The most important factor is age, with a nearly $50 \%$ increased risk of severe hemorrhage per decade in those aged more than 40 years. Arterial hypertension is also a significant risk factor [4-6].

Despite the standardization of laboratory procedures, agreement on therapeutic ranges and the introduction of new anticoagulants into the therapeutic arsenal, the occurrence of hemorrhagic events remains significant [7-9].

The aim of our study was to register and analyze the most severe bleeding events revealed during CT scan examinations over a 1-year period at our University Hospital and to evaluate the role of ACs and APAs in their occurrence.

\section{Methods}

\section{Patients}

Between April 1, 2011 and March 31, 2012, we performed a monocentric retrospective study that included all patients who had undergone a CT scan for a non-traumatic severe hemorrhage. Exclusion criteria were represented by all suspected traumatic contexts, hemorrhages caused by an underlying tumor, a vascular malformation, or a postoperative bleeding.

During this period, 93 patients were included (50 males, 43 females), mean age $76 \pm 11$ years, who had been referred by various departments: emergency $(n=75)$, cardiology $(n=7)$, recovery unit $(n=5)$, rheumatology $(n=2)$, infectious-disease department $(n=2)$, and internal medicine $(\mathrm{n}=2)$.

Seventy-three patients underwent a cerebral, 16 an abdominal, and 4 a lower-limb CT scan. Data were collected using Xplore Exploitation software, version 6.2.814 (EDL, Santé La Seine sur Mer, France), which records all reports from CT scans performed in our Center (22,076 over this period), and this information was then complited with the patients' hospital-examination files. The studied parameters are listed in Table 1.

The 93 patients were divided into two groups: group 1, those who did not received ACs or APAs $(n=32)$ and group 2, those who were treated with ACs and/or APAs $(n=61)$ (Table 2). Details on the AC and APA treatments are presented in Table 3. Thirty eight patients received ACs, 16 received APAs, 6 received both ACs and APAs, and one patient received two APAs. The AC and/or APA indications were atrial fibrillation (39\%), thromboembolic disease (13\%), coronary-artery disease (12\%), mechanical prosthesis (5\%), and a previous history of stroke (5\%).

Anticoagulation reference thresholds for the international normalized ratio (INR) were between 2.5 and 3.5 for mitral
Table 1 Indications and results of CT-scans in patients with a hemorrhagic event

\begin{tabular}{lll}
\hline Indications and results of CT-scans & Number & Percentage \\
\hline Consciousness disorders & 39 & 42 \\
Headache & 13 & 14 \\
Focal neurological signs & 59 & 63 \\
Abdominal pain & 15 & 16 \\
Anemia & 21 & 24 \\
Thigh swelling & 4 & 4 \\
Results & & \\
Cerebral CT-scan (intracranial hemorrhage) & 73 & 78 \\
Subarachnoid hemorrhage & 5 & \\
Peri-cerebral hematoma & 12 & \\
Intraparenchymal hematoma & 62 & \\
Intraventricular hemorrhage & 34 \\
Cerebral herniation & 36 \\
Abdominal and lower-limb CT-scan & 20 \\
(muscular hematoma) & 22 \\
Rectus abdominis hematoma & 11 \\
Iliopsoas hematoma & 5 \\
Quadriceps hematoma & 4 & \\
\hline
\end{tabular}

mechanical prosthesis and between 2 and 3 for the other indications.

This descriptive, retrospective monocentric study was conducted according to ethical principles for medical research involving human subjects in French university hospitals [10].

\section{Statistical analyses}

The statistics were computed using STATA V10 software (Stata Corp, College Station, Texas, USA). Data are expressed as frequencies and associated percentages for categorical data, and as means \pm standard deviations for continuous data.

The categorical data from the two treatment groups were compared using the chi-squared test (or Fisher's exact test, if necessary). Continuous data were compared using Student's $t$-test (or the KruskalWallis test, if necessary), normality was verified by the Shapiro-Wilk test and homoscedasticity by the FisherSnedecor test.

The risk ratio, for patients who received AC or APA, for a cerebral hemorrhage and subsequent cerebral herniation, a rectus sheath, iliopsoas bleeding, or a quadriceps hematoma were shown with their corresponding 95\% confidence intervals.

All tests were two-sided, with the type 1 error set at $\alpha=0.05$. 
Table 2 Comparison between patients treated with anticoagulants (AC) or antiplatelet agents (APA) and those not treated with either

\begin{tabular}{|c|c|c|c|}
\hline & $\begin{array}{l}\text { Group 1: } \\
\text { Not treated: } \\
n=32\end{array}$ & $\begin{array}{l}\text { Group 2: } \\
\text { AC or APA: } \\
n=61\end{array}$ & $p$-value \\
\hline Intracranial hemorrhage & $32(100)$ & $41(67)$ & NA \\
\hline Cerebral herniation (mm) & $7.1 \pm 2.7$ & $9.8 \pm 4.6$ & 0.04 \\
\hline Muscular hematoma & $0(0)$ & $20(33)$ & $<0.0001$ \\
\hline $\begin{array}{l}\text { Rectus abdominis, } \\
\text { iliopsoas hematoma }\end{array}$ & $0(0)$ & $16(24)$ & 0.001 \\
\hline Quadriceps hematoma & $0(0)$ & $4(7)$ & 0.30 \\
\hline Muscular hematoma (mL) & NA & $363 \pm 349$ & NA \\
\hline Anemia ( $\mathrm{Hb}<10 \mathrm{~g} / \mathrm{dL})$ & $3(3)$ & $18(30)$ & 0.02 \\
\hline Hematocrit (\%) & $39.3 \pm 6$ & $35.6 \pm 8.2$ & 0.04 \\
\hline Blood platelets & $221 \pm 64$ & $247 \pm 88$ & 0.28 \\
\hline Transfusion of globular sediment & $1(3)$ & $7(11)$ & 0.17 \\
\hline Death & $5(15)$ & $17(28)$ & 0.19 \\
\hline $\begin{array}{l}\text { Delay between CT-scan and } \\
\text { death (days) }\end{array}$ & $13.4 \pm 21.1$ & $7.8 \pm 19.9$ & 0.04 \\
\hline $\begin{array}{l}\text { In-hospital stay period of } \\
\text { surviving patients (days) }\end{array}$ & $27.7 \pm 34.3$ & $19.8 \pm 26.4$ & 0.35 \\
\hline
\end{tabular}

Data are mean \pm standard deviation, median (interquartile range) or number (\%). Abbreviations: $\mathrm{mm}$ millimeter, $\mathrm{mL}$ milliliter, $\mathrm{g} / \mathrm{dL}$ gram per deciliter, NA not applicable.

\section{Results}

According to international guidelines and our university hospital's heart-surgery department's recommendations $[4,11,12]$ the indications for AC and APA treatments were all justified. APA treatments were prescribed mainly

Table 3 Prescribed anticoagulant and antiplatelet agents

\begin{tabular}{lll}
\hline $\begin{array}{l}\text { Anticoagulant treatments and } \\
\text { antiplatelet agents }\end{array}$ & Number & Percentage \\
\hline Anticoagulants & 37 & 40 \\
Acenocoumarol & 8 & \\
Fluindione & 21 & \\
Coumadin & 4 & \\
Unfractionated heparin & 1 & 18 \\
Low molecular weight heparin & 3 & \\
Antiplatelet agents & 17 & \\
Aspirin & 13 & \\
$\quad$ Ticlopidine & 1 & \\
Clopidogrel & 3 & \\
Antiplatelet bitherapy & 1 & \\
Aspirin, clopidogrel & 1 & \\
Anti-vitamin-K + antiplatelet agents & 6 \\
Fluindione + aspirin & 5 \\
Coumadin + aspirin & 1 & \\
\hline
\end{tabular}

for coronary and/or peripheral arteriosclerosis; ACs, unfractionated heparin, Low Molecular Weight Heparin (LMWH) and VKAs were prescribed for thromboembolic disease, atrial fibrillation or in postoperative orthopedic patients.

Four patients had an INR between 3 and 4, one patient between 4 and 6 , and another had a ratio $>6$. Among these patients, 2 patients had a muscular hematoma and 4 patients had an intracranial hemorrhage. Comparisons between patients treated and not treated by $\mathrm{AC}$ and APA are listed in Table 2.

Muscular hematoma occurred in $22 \%$ of cases $(n=20)$, among which $17 \%(\mathrm{n}=16)$ were of the rectus sheath or iliopsoas, and $4 \%(n=4)$ were quadriceps hematomas. Muscular bleedings and hematomas occurred exclusively in patients treated by AC or APA. This difference was statically significant $(\mathrm{p} \quad<0.0001)$ (Table 2).

All patients $(\mathrm{n}=4)$ with a quadriceps hematoma received an anticoagulation treatment (AC exclusively in 3 patients, and AC + APA in 1 case) (Table 4). Five cases of iliopsoas hematomas were recorded (all in patients treated by $\mathrm{AC}$ ), and 11 patients had a rectus sheath hematoma (9 received $\mathrm{AC}, 1$ had $\mathrm{APA}$, and 1 had a bitherapy of AC + APA) (Table 4). The estimated risk of soft tissue hematoma was 3.9 [1-15] in patients who received $\mathrm{AC}$ compared to patients treated by antiplatelet therapy (Figures 1 and 2).

The average muscular hematoma volume was $363 \pm$ $249 \mathrm{~mL}$, and was associated with a statistically significant decrease in hemoglobin and hematocrit (p 0.02 and 0.04, respectively) (Table 2).

An intracranial hemorrhage $(n=73)$ was the most common bleeding event, $78 \%$ of the observed bleedings (0.03\% of the total 2274 emergency cerebral CT scans performed during this period). A cerebral hemorrhage was observed in $67 \%(\mathrm{n}=41)$ of patients treated with $\mathrm{AC}$ and/or APA (Table 2).

Among patients with an intracranial hemorrhage, 32 (44\%) received neither AC nor APA treatment, 21 had a single AC treatment, 15 had a single antiplatelet therapy, 4 had a bitherapy (AC + APA), and 1 had a double antiplatelet therapy (Table 4).

Cerebral herniation, estimated by the displacement of medial brain structures (Figure 3), was significantly more important in patients treated by AC and/or APA $(9.8 \pm$ $4.6 \mathrm{~mm})$ compared to group 1 patients $(7.1 \pm 2.7 \mathrm{~mm}$; $\mathrm{p}=0.04$ ). The risk of cerebral herniation was higher in patients who received $\mathrm{AC}$ compared to patients who received a single APA therapy ( $62 \%$ vs. $31 \%$, respectively, $\mathrm{RR}=2.3[0.9-5.7])$.

Among the 93 patients, 22 died (24\%). In 19 cases (86\%) the cause of death was an intracranial hemorrhage and of these, $14(74 \%)$ were treated with AC or APA. 
Table 4 Incidence of hemorrhages with the different treatments: anticoagulants (AC) and/or antiplatelet agents (APA), or no drug therapy

\begin{tabular}{|c|c|c|c|c|c|}
\hline & Not treated: $n=32$ & Only AC: $n=38$ & APA: $n=16$ & AC + APA: $n=6$ & Double APA: $n=1$ \\
\hline Intracranial hemorrhage & $32(100)$ & $21(55)$ & $15(94)$ & $4(67)$ & $1(100)$ \\
\hline Muscular hematoma: $n=20$ & $0(0)$ & $17(45)$ & $1(6)$ & $2(33)$ & $0(0)$ \\
\hline Quadriceps $(n=4)$ & $0(0)$ & $3(8)$ & $0(0)$ & $1(17)$ & $0(0)$ \\
\hline Rectus abdominis $(n=11)$ & $0(0)$ & $9(24)$ & $1(6)$ & $1(17)$ & \\
\hline Iliopsoas $(n=5)$ & $0(0)$ & $5(13)$ & $0(0)$ & $0(0)$ & $0(0)$ \\
\hline Cerebral-hematoma volume (mL) & $42.9 \pm 45.5$ & $65.8 \pm 46.4$ & $28 \pm 37.7$ & $23.3 \pm 44.5$ & $0(0)$ \\
\hline Transfusion: $n=8$ & $1(3)$ & $7(18)$ & $0(0)$ & $0(0)$ & $0(0)$ \\
\hline Anemia ( $\mathrm{Hb}<10 \mathrm{~g} / \mathrm{dL}$ ): $n=21$ & $3(9)$ & $15(39)$ & $1(6)$ & $2(33)$ & $0(0)$ \\
\hline Hematocrit (\%) & $39.3 \pm 6$ & $33.8 \pm 9.2$ & $39.4 \pm 4.2$ & $34.9 \pm 7.9$ & $\mathrm{MD}$ \\
\hline Deaths: $n=22$ & $5(16)$ & $13(34)$ & $4(25)$ & $0(0)$ & $0(0)$ \\
\hline Delay between CT-scan and death (days) & $13.4 \pm 21.1$ & $2.8 \pm 5$ & $24 \pm 39.5$ & $0(0)$ & $0(0)$ \\
\hline In-hospital stay (days) & $15[3-37]$ & $11.5[6-19.5]$ & $12[6-24]$ & $15[4-78]$ & $2[2-2]$ \\
\hline
\end{tabular}

Data are mean \pm standard deviation, median (interquartile range) or number (\%). MD: Missing Data.

Abbreviations: $\mathrm{mm}$ millimeter, $\mathrm{mL}$ milliliter, $\mathrm{g} / \mathrm{dL}$ gram per deciliter, $N A$ not applicable.

The time until death was statistically shorter for group 2 patients compared with group 1: $7.8 \pm 19.9$ vs. $13.4 \pm$ 21,1 days, $\mathrm{p}=0.04$ (Table 2) and it was even shorter for patients who received AC ( $2.8 \pm 5$ days) when compared to all other treatments. Patients who had a bitherapy $(\mathrm{AC}+\mathrm{APA}$ or APA + APA) were all alive at the end of this study (Table 4).

\section{Discussion}

In our series, which included patients who had suffered a severe hemorrhage detected by CT scan, the intracranial location was predominant. In addition, these intracranial hemorrhages were more severe when patients received AC or APA therapy. Muscular bleedings and hematomas

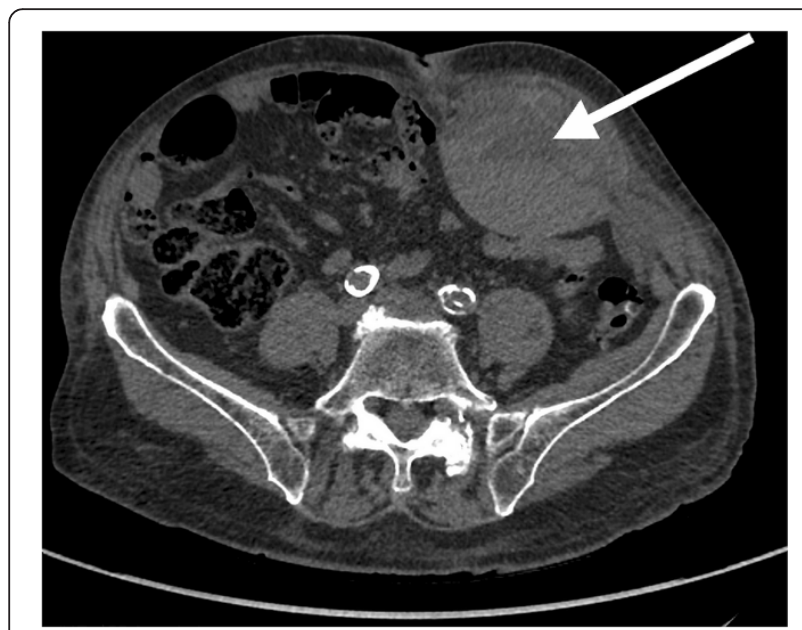

Figure 1 Abdominal CT scan. Hematoma of the rectus abdominis (White arrow). were not observed in patients who did not receive any AC or APA.

In our patient population, the main fatal hemorrhagic event was intracranial hemorrhage (86\%). In France these account for $10-15 \%$ of the total number of cerebrovascular events, $10-20$ cases per 100,000 inhabitants [6]. Their incidence per year is between 0.3 and $0.6 \%$.

Palareti et al., [13] in a series that included severe as well as minor hemorrhages, reported 153 hemorrhagic complications (7.6 per 100 patient-years), of which five were fatal (all cerebral hemorrhages, 0.25 per 100 patient-years), 23 were major (1.1), and 125 were minor (6.2).

Our study did not find any significant difference in the occurrence of intracranial hemorrhage depending on

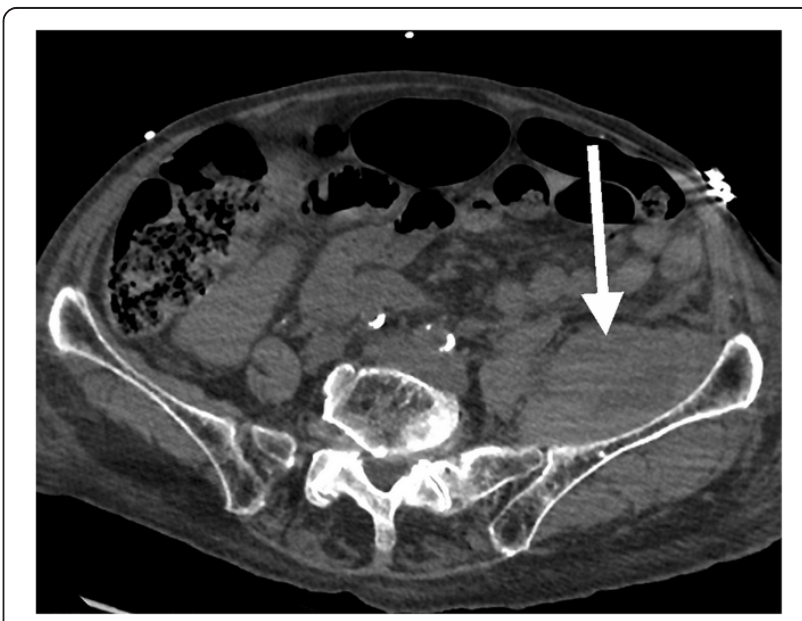

Figure 2 Abdominal CT scan. Hematoma of the left iliopsoas (White arrow) 


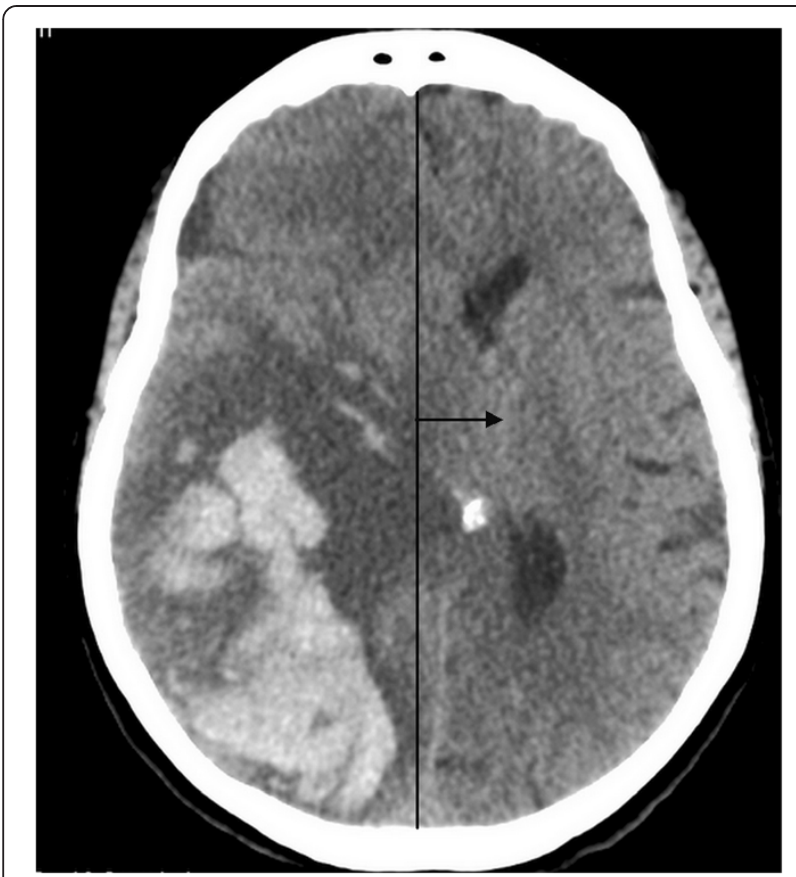

Figure 3 Cranial CT scan. Right parietal occipital hematoma with cerebral oedema and left displacement of the medial brain structures (Black arrow)

whether the patient received ACs or not; however, worsening elements of a cerebral hemorrhage, such as the volume of the cerebral hematoma, were statistically significant in patients receiving ACs.

Cucchiara et al.'s study [14] confirms this finding. In their series, the initial volume, the progression, and the mortality rate from intracranial hemorrhage were greater in patients who received VKAs compared to those who did not receive ACs.

Tonolini et al. [15] reported that bleeding occurred in almost every muscle group in patients treated with ACs or APAs. On CT scan, the appearance of muscular hemorrhages depends on its location, and bleeding rate. Rectus sheath and iliopsoas are the most common locations. Patients usually complain with acute abdominal pain and distension, associated with a fall in hematocrit and often a hypovolemic shock. In our series, severe muscular hematomas that required a CT scan occurred exclusively in patients who had received AC or APA therapy.

Venous thromboembolic disease and prevention of cardiac arterial emboli during atrial fibrillation are the two main indications for prescribing ACs $[1,4,16]$. In our study, atrial fibrillation and thromboembolic venous disease were the most frequent indications, accounting for, respectively, $38.5 \%$ and $13 \%$ of the cases. In a study that included 188,740 elderly patients (aged $>65$ years), Van Walraven et al. [17] reported that 10,020 people
(5.3\%) were treated with VKAs (3.5\% of the total population). People who received ACs had a mean age of 77 years, and $50 \%$ were men. They spent $26.7 \%$ of their VKA exposure time with an INR $<2$ and $14.2 \%$ of the time with an INR $>3$. They had an overall hemorrhagic rate of $6 \%$ per year. Bleeding rates increased significantly when INR exceeded 3. As reported by Butchart [17] important INR variations are as important as the high level of INRs to explain some hemorrhagic accidents due to vitamin $\mathrm{k}$ antagonists and only a careful INR control with dedicated devices can decrease bleeding complications due to this variations [18].

Old age is a risk factor for hemorrhagic bleedings in patients receiving ACs or APAs [1,4,16,19], particularly in those aged $>75$ years, but also for patients with a prior history of intracranial hemorrhage [19].

Many studies show that there is a high association between age and hemorrhagic risk. In our series, cerebral hemorrhagic events occurred in $62.3 \%$ of patients aged $>65$ years, but there was no statistically significant difference in younger patients. Similarly, the role of arterial hypertension, as well as described by some authors $[5,6]$, was not evidenced in our experience. This could be related to our study population, which included only severe hemorrhagic events detected by CT scan. After AC treatment, arterial hypertension is the second most important risk factor for intracranial hemorrhage occurrence [20,21]. Alcohol and tobacco are other risk factors [20].

\section{Study limitations}

This descriptive study is a collection of severe hemorrhagic events, detected by a CT-scan in our Center, without a comparative control population. In addition, our selection method, which only included those who benefited from a computerized CT scan, could have excluded patients with milder hemorrhagic events which did not require a CT scan, and also rapidly mortal hemorrhages. The timeframe of our monocentric study was too short to allow exhaustive analysis. A multicenter study with a longer follow-up period is needed to confirm our preliminary results.

\section{Conclusion}

Severe hemorrhages are preponderantly intracranial and have a high mortality rate, regardless of the patient's exposure to anticoagulant or antiplatelet agents. This study confirms that muscular and soft-tissue hemorrhagic events exclusively occur in patients who received AC and/or APA therapies. Further investigations are needed to monitor the effects of new anticoagulant and antiplatelet agents.

\section{Abbreviations}

AC: Anticoagulants; APA: Antiplatelets agents; CT scan: Computed Tomography scanner; INR: International Normalized Ratio; VKA: Vitamin K antagonists; LMWH: Low molecular weight heparin. 


\section{Competing interests}

The authors declare that they have no competing interests.

\section{Authors' contributions}

OR did the data acquisition and participated in manuscript conception. AA did the data interpretation and participated in manuscript design. AM performed the statistical analysis. AHA did data acquisition. LB and LC participated in study conception and did the final approval. KA: conceived the study, and participated in its design and coordination and helped to draft the manuscript. All authors read and approved the final manuscript.

\section{Acknowledgements}

The authors would like to thank Dr. Enrica Dorigo for her careful editing of the manuscript.

\section{Author details}

'pôle Imagerie et Radiologie Interventionnelle CHU de Clermont-Ferrand, ISIT, UMR CNRS 6284 - université d'Auvergne Clermont Hospital, Clermont-Ferrand, France. ${ }^{2}$ Bio-statistics unit, Délégation Recherche Clinique \& Innovation, Clermont-Ferrand University Hospital, Clermont-Ferrand, France. ${ }^{3}$ Heart surgery Department, G. Montpied Hospital, Clermont-Ferrand University Hospital, Clermont-Ferrand 63000, France. ${ }^{4}$ INRA, UMR 1019 Nutrition Humaine, Saint Genès Champanelle, France.

Received: 18 June 2014 Accepted: 26 September 2014

Published online: 15 October 2014

\section{References}

1. Dunning J, Versteegh M, Fabbri A, Pavie A, Kolh P, Lockowandt U, EACTS Audit and Guidelines Committee, Nashef SA: Guideline on antiplatelet and anticoagulation management in cardiac surgery. Eur I Cardiothorac Surg 2008, 34:73-92.

2. Gras-Champel V, Brenet-Dufour V, Moragny J, Masson H, Davidau E, Masmoudi K, Andrejak M: Quantification of the part allocated to the preventability of vitamin $\mathrm{K}$ antagonists therapy bleeding events. Therapie 2010, 65:261-268.

3. Pouyanne P, Haramburu F, Imbs JL, Bégaud B: Admissions to hospital caused by adverse drug reactions: cross sectional incidence study. French Pharmacovigilance Centres. BMJ 2000, 320:1036.

4. Lansberg MG, O'Donnell MJ, Khatri P, Lang ES, Nguyen-Huynh MN, Schwartz NE, Sonnenberg FA, Schulman S, Vandvik PO, Spencer FA, Alonso-Coello P, Guyatt GH, AkI EA: American College of Chest Physicians. Antithrombotic and thrombolytic therapy for ischemic stroke: Antithrombotic Therapy and Prevention of Thrombosis, 9th ed: American College of Chest Physicians Evidence-Based Clinical Practice Guidelines. Chest 2012, 141:e601S-36S.

5. Cosserat F, Colnat-Coulbois S, Klein O, Audibert G, Petitpain N, Tréchot P, Auque J: Hémorragies intracrâniennes et anticoagulants oraux: étude des facteurs pronostiques à partir d'une série de 186 cas. Neurochirurgie 2009, 55S:11-16.

6. Grillo $P$, Velly $L$, Bruder $N$ : Accident vasculaire cérébral hémorragique: nouveautés sur la prise en charge. Ann Fr Anesth Reanim 2006, 25:868-873

7. Poli D, Antonucci E, Testa S, Tosetto A, Ageno W, Palareti G: Result of a prospective collaborative study on elderly patients followed by Italian centres for anticoagulation. Circulation 2011, 124:824-829.

8. Connolly SJ, Ezekowitz MD, Yusuf S, Eikelboom J, Oldgren J, Parekh A, Pogue J, Reilly PA, Themeles E, Varrone J, Wang S, Alings M, Xavier D, Zhu J, Diaz R, Lewis BS, Darius H, Diener HC, Joyner CD, RE-LY Steering Committee and Investigators, Wallentin L: Dabigatran versus Warfarin in Patients with Atrial fibrillation. N Engl J Med 2009, 361:1139-1151.

9. Patel MR, Mahaffey KW, Garg J, Pan G, Singer DE, Hacke W, Breithardt G, Halperin JL, Hankey GJ, Piccini JP, Becker RC, Nessel CC, Paolini JF, Berkowitz SD, Fox KA, Califf RM, ROCKET AF Investigators: Rivaroxaban versus warfarin in nonvalvular atrial fibrillation. $N$ Engl J Med 2011, 365:883-91.

10. Claudot F, Alla F, Fresson J, Calvez T, Coudane H, Bonaiiti-Pellié C: Ethics and observational studies in medical research: various rules in a common framework. Int J Epidemiol 2009, 38(4):1104-1108.
11. Azarnoush K, Camilleri L, Aublet-Cuvelier B, Geoffroy E, Dauphin C, Dubray C, De Riberolles C: Results of the first randomized French study evaluating self-testing of the International Normalized Ratio. J Heart Valve Dis 2011, 20:518-525.

12. Coppens M, Eikelboom JW, Hart RG, Yusuf S, Lip GY, Dorian P, Shestakovska O, Connolly SJ: The CHA2DS2-VASc score identifies those patients with atrial fibrillation and a CHADS2 score of 1 who are unlikely to benefit from oral anticoagulant therapy. Eur Heart J 2013, 34:170-176.

13. Palareti G, Leali N, Coccheri S, Poggi M, Manotti C, D'Angelo A, Pengo V, Erba N, Moia M, Ciavarella N, Devoto G, Berrettini M, Musolesi S: Bleeding complications of oral anticoagulant treatment: an inception-cohort, prospective collaborative study (ISCOAT). Italian Study on Complications of Oral Anticoagulant Therapy. Lancet 1996, 348:423-428.

14. Cucchiara B, Messe S, Sansing L, Kasner S, Lyden P: Hematoma Growth in Oral Anticoagulant Related Intracerebral Hemorrhage. Stroke 2008, 11:2993-2996.

15. Tonolini M, Ippolito S, Patella F, Petullà M, Bianco R: Hemorrhagic complications of anticoagulant therapy: role of multidetector computed tomography and spectrum of imaging findings from head to toe. Curr Probl Diagn Radiol 2012, 41:233-247.

16. Bauersachs RM: Use of anticoagulants in elderly patients. Thromb Res 2012, 129:107-115.

17. Butchart EG, Payne N, Li HH, Buchan K, Mandana K, Grunkemeier GL: Better anticoagulation control improves survival after valve replacement. J Thorac Cardiovasc Surg 2002, 123:715-723.

18. Azarnoush K, Dorigo E, Pereira B, Dauphin C, Geoffroy E, Dauphin N, D'Ostrevy N, Legault B, Camilleri L: Mid-term results of self-testing of the international normalized ratio in adults with a mechanical heart valve. Thromb Res 2013, Sep 16. In press.

19. Van Walraven C, Oake N, Wells PS, Forster AJ: Burden of potentially avoidable anticoagulant-associated hemorrhagic and thromboembolic events in the elderly. Chest 2007, 131:1508-1515.

20. Feldmann E, Broderick JP, Kernan WN, Viscoli CM, Brass LM, Brott T, Morgenstern LB, Wilterdink JL, Horwitz Rl: Major risk factors for intracerebral hemorrhage in the young are modifiable. Stroke 2005, 36:1881-1885.

21. Brott $T$, Thalinger $K$, Hertzberg $V$ : Hypertension as a risk factor for spontaneous intracerebral hemorrhage. Stroke 1986, 17:1078-1083.

doi:10.1186/s13019-014-0166-9

Cite this article as: Risch et al: Severe non-traumatic bleeding events detected by computed tomography: do anticoagulants and antiplatelet agents have a role? Journal of Cardiothoracic Surgery 2014 19:166.

\section{Submit your next manuscript to BioMed Central and take full advantage of:}

- Convenient online submission

- Thorough peer review

- No space constraints or color figure charges

- Immediate publication on acceptance

- Inclusion in PubMed, CAS, Scopus and Google Scholar

- Research which is freely available for redistribution 